\title{
Seismic strengthening of churches as a part of earthquake renewal in the Posočje region, Slovenia
}

\author{
M. Uranjek, B. Dolinšek \& S. Gostič \\ Building and Civil Engineering Institute ZRMK, Slovenia
}

\begin{abstract}
Seismic activity of the Posočje region, located in the north-east of Slovenia is considerably high. Four major earthquakes have hit this area in the last three decades. Among buildings to be repaired and/or strengthened, churches represent a significant share of the building fund. Churches which are often classified as cultural heritage are usually an indispensable part of settlements and their identity. In order to preserve these prominent buildings for future generations, there is a need for attentive and consistent planning of preliminary research, strengthening procedures and their execution. If compared to ordinary buildings in the Posočje region, which are typically characterized by inadequate building quality, churches in this region are of better quality. Nevertheless, on account of their typical design, strengthening procedures are more complex and demanding, and therefore, adequate seismic resistance is harder to achieve compared to ordinary buildings. In the paper, some of the basic strengthening procedures applied on churches in the Posočje region are presented.
\end{abstract}

Keywords: church, strengthening, earthquake renewal, seismic resistance.

\section{Introduction}

Seismic activity of the Posočje region, located in the north-east of Slovenia is considerably high, namely four major earthquakes hit this area in last three decades. First earthquake in May 1976 reached the grade IX.-X. and the second one in September 1976 the grade of IX. according to EMS scale. Earthquakes in 1976 caused damage to around 12.000 buildings, of which 4.200 were completely destroyed. Consequently people in this area became aware of the danger and begun to construct buildings which were safer and more resistant to 
seismic actions. In 1998 the earthquake reaching the grade of VII.-VIII. damaged 4.000 buildings and destroyed 500 of them. The latest earthquake in 2004 with the grade of VI.-VII. caused damage to 1.800 buildings and destroyed 20 of them. Among buildings that have so far been repaired or some of the strengthening procedures were carried out, there is well over 150 buildings of cultural heritage, of which 54 churches. Because of their typical structural system which usually has to remain intact, selection of appropriate strengthening measures is a complex and demanding process. Therefore it is in most cases harder to achieve adequate seismic resistance for churches, than for ordinary buildings. Radical strengthening measures such as new reinforced concrete frames, or even additional load-bearing walls, which can be used to improve earthquake resistance of residential buildings, are not eligible for churches. In case of churches, adequate load bearing capacity of separate structural elements and the integrity of structure as a whole has to be achieved without visible (or distracting) modifications of the basic structural system.

\section{Typical structural design and earthquake damage of churches}

Although churches were mostly built by experience without detailed calculations, structural elements such as "sewn" corners of walls and iron wall ties (fig. 1) are proof that the builders of the past were familiar with the principles of improving the structural integrity of buildings subjected to seismic loads.
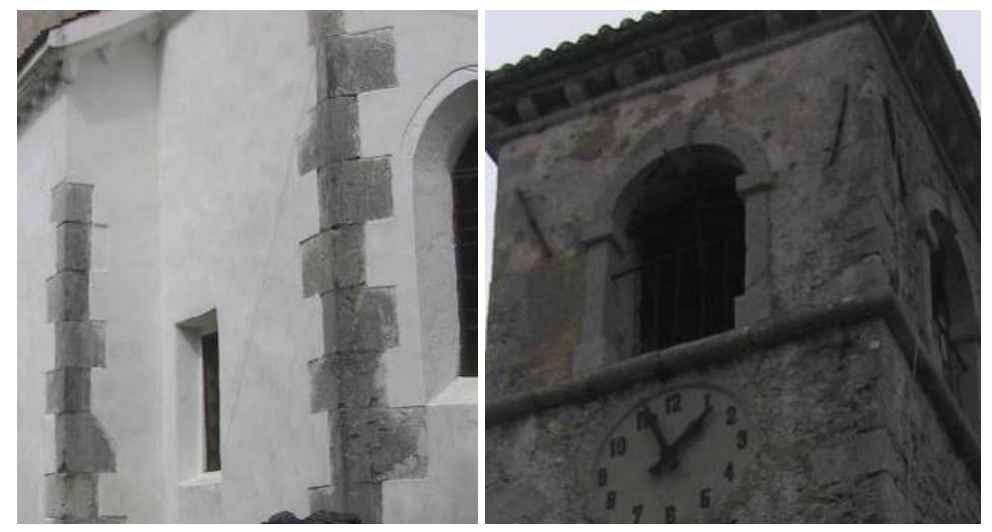

Figure 1: $\quad$ Sewn corners of a St. Michael church in Ljubinj and iron wall ties of the church of St. Andrew in Svino.

Churches are characterized by a complex structural system constructed out of several structural parts with different geometry and mechanical properties. Consequently, structural parts such as portal, nave, presbytery, bell tower (usually connected with nave, seldom self supporting) and sacristy, have rather 
different response to seismic action. Nave as a central structural part of a church is characterised with high walls which are often not properly connected and anchored at floor and roof levels and in addition, most naves have no loadbearing walls in transverse direction, which makes them irregular in terms of earthquake resistant design. The irregularity of bell towers as a second most discernible part of a structural system is mainly due to its height/floor area ratio. Damage induced by an earthquake often occurs at connections and intersections of different structural parts of the church building. Usually the first elements to suffer the earthquake damage are heavy console elements e.g. campanulas and decorative elements such as jutting roof, especially if not properly anchored and connected to the base structure. Due to movements and oscillations of supporting walls, cracks are often formed in arches and vaults, but also in supporting walls themselves. On fig. 2 damage that occurred on bell tower of a church of St. Anton the Hermit and the console structure of a historical building in Bovec is presented.
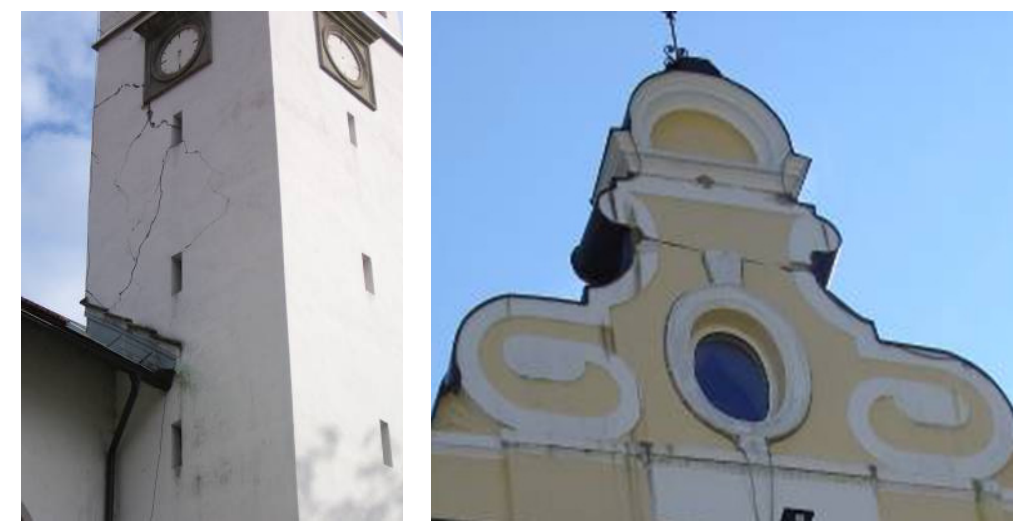

Figure 2: Typical damage on bell tower of a church and console structure of a historical building.

\section{Preliminary investigation}

In order to maximize the accuracy of assessing the morphology, damage and mechanical properties of the structure, several methods of investigation should be used. A combination of non-destructive (NDT) and minor destructive (MDT) investigation techniques has proven to be very efficient. NDT techniques such as GPR measurement and pulse sonic tests can be performed on wider area of the wall, while MDT techniques (surface and depth sounding, coring, flat jack test), are preferred to be done locally in order to minimize the damage. In some rare cases (because of complexity and considerable costs) destructive (DT) investigation techniques may be performed. 


\subsection{NDT investigation techniques}

GPR (Ground Penetrating Radar) measurements can be used to assess the morphology of the structure. The method is based on the emission and reflection of very short electromagnetic impulses by an antenna system. Reflection of the emitted impulses occurs at the interfaces between materials with different permittivities or conductivities, such as the interface between air (i.e. the voids) and the building material. Because the propagation velocity and the signal penetration depend on the electric and dielectric properties, the boundaries between different materials can be distinguished. GPR can be performed before and after grout injection to evaluate the quality of this strengthening technique (fig. 3).
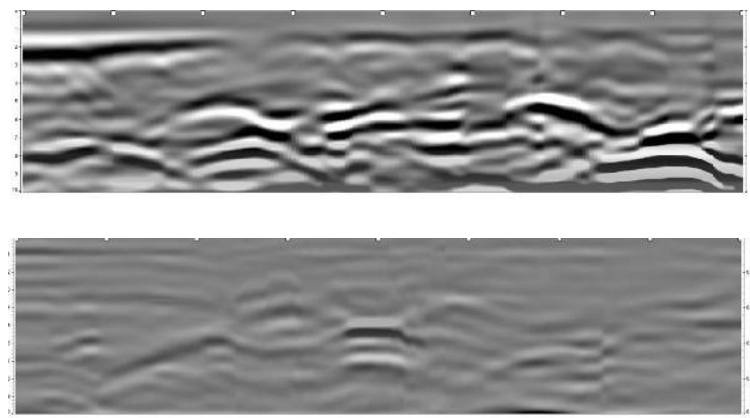

Figure 3: GPR profiles before (above) and after (below) grout injection.

Thermo-graphic measurements are usually used for detecting hidden mistakes in building envelopes, but the method can be successfully applied in the monitoring of the grout injection quality (fig. 4). Thermo-graphical measurements enable us to identify the wall areas with increased surface
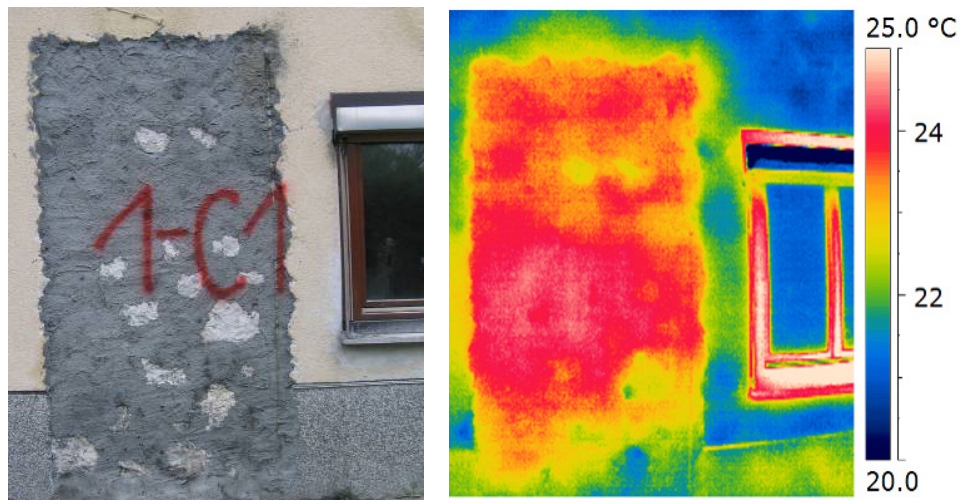

Figure 4: Digital and thermo-graphic photography of the wall 28 hours after grouting. 
temperature during a given time interval after injection when, because of the hydration process, heat is released. It has to be emphasized that the measured temperature of the wall depends not only on the hydration but also on the external temperature. This is why the results need to be interpreted with knowledge of the external temperatures at the time of measurement, and a comparison of the measured temperatures between the injected and non-injected parts of the wall.

Sonic pulse test is based on the generation of sonic impulses at a selected point of the structure. Based on the time that the impulse takes to cover the distance between the transmitter and the receiver, the quality and homogeneity of the tested structure can be determined.

\subsection{MDT investigation techniques}

MDT investigation techniques such as surface and in-depth probing (fig. 5) and coring (fig. 6) on selected areas of the investigated building's structure (walls, foundations), reveal the morphology of the structure at tested positions.
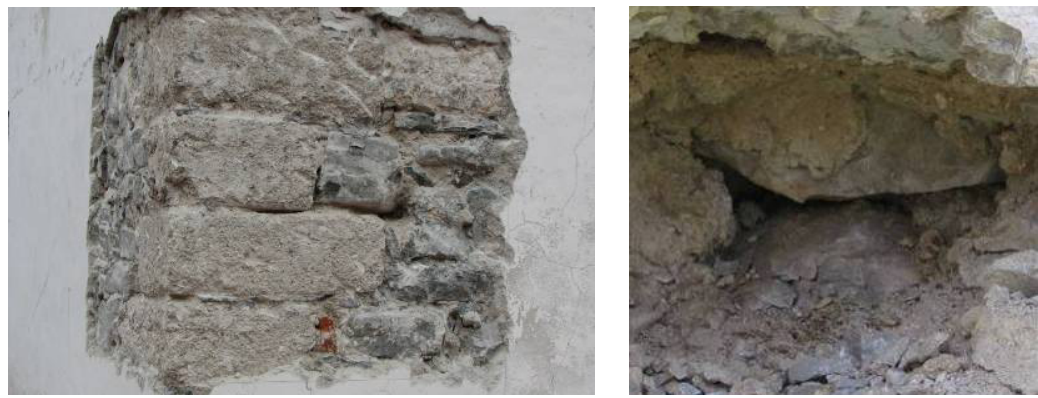

Figure 5: $\quad$ Surface and in-depth probing of the walls.
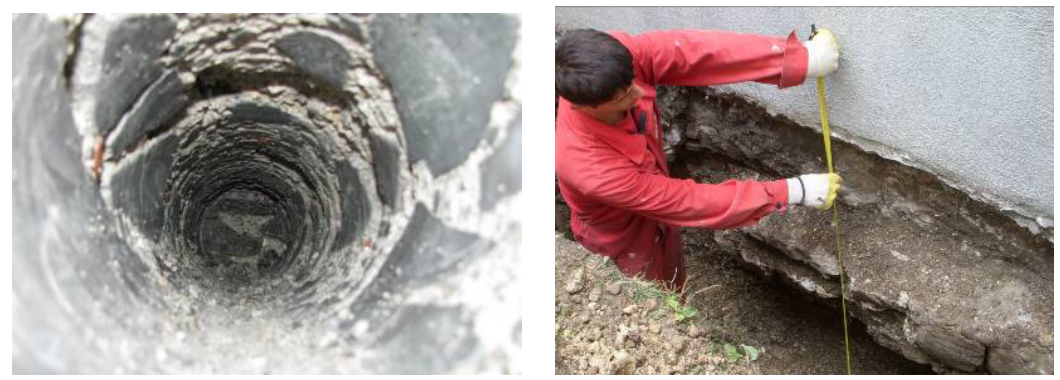

Figure 6: Coring of the walls and in-depth probing of foundations.

Occasionally, more demanding MDT methods such as double flat jack test are used. Flat jack tests enable us to determine the deformability characteristics of the tested wall area. At first, two parallel cuts are made, after which a thin flatjack is placed inside each of the cuts, and the oil pressure operating the jack is 
gradually increased. LVDT's placed between the two cuts enable the monitoring of vertical and lateral deformations during the test (fig. 7).
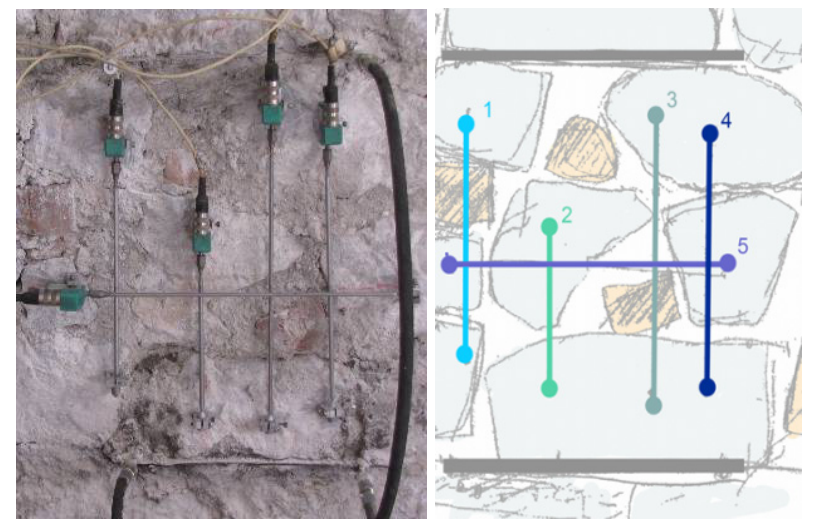

Figure 7: $\quad$ Set up of the measuring equipment for the double flat jack test.

\subsection{DT investigation techniques}

DT tests are usually carried out in-situ, although it is possible to cut out parts of a structure, carefully transport them, and proceed with the tests in the laboratory. Among DT investigation techniques in Slovenia, several in-situ shear tests were performed, usually on fixed-end wall specimens. Such specimens are loaded laterally by means of a hydraulic actuator by increasing the displacement up to the limit state. In-situ shear tests enable us to determine the shear resistance to lateral load and effective stiffness of the tested walls.

\section{Evaluation of seismic resistance}

Generally the seismic resistance of existing buildings is verified twice: in their existing state and state after strengthening. Seismic analysis of the building in its existing state reveals critical areas which have to be strengthened, while the basic aim of "after" analysis is to determine the level of seismic resistance reached for strengthened structure. For most churches under earthquake renewal in Posočje, seismic resistance was evaluated by means of non-linear static analysis using pushover method, based on the storey-mechanism approach. Based on the idealized bi-linear hysteresis envelopes of the individual walls the storey resistance envelope is calculated step-by-step by increasing the imposed displacements. In addition to other assumptions, the method assumes that the floors are rigid enough to allow distribution of seismic forces onto the walls and that the first vibration mode shape is the predominant one. The method can quite accurately describe the behaviour of simple masonry buildings with regular distribution of load bearing walls in both horizontal directions and adequate configuration of building in elevation. However, in case of more complex structural systems such as churches, with irregular structural layout and flexible 
wooden floors, the drawbacks of the method become more obvious. Therefore, in order to determine the critical failure mechanism of the structure during an earthquake, the method can be used by performing seismic analysis at different levels, depending on geometric characteristics of the structure (fig. 8). The division of structure into macro elements correspond to the observed crack patterns after an earthquake.

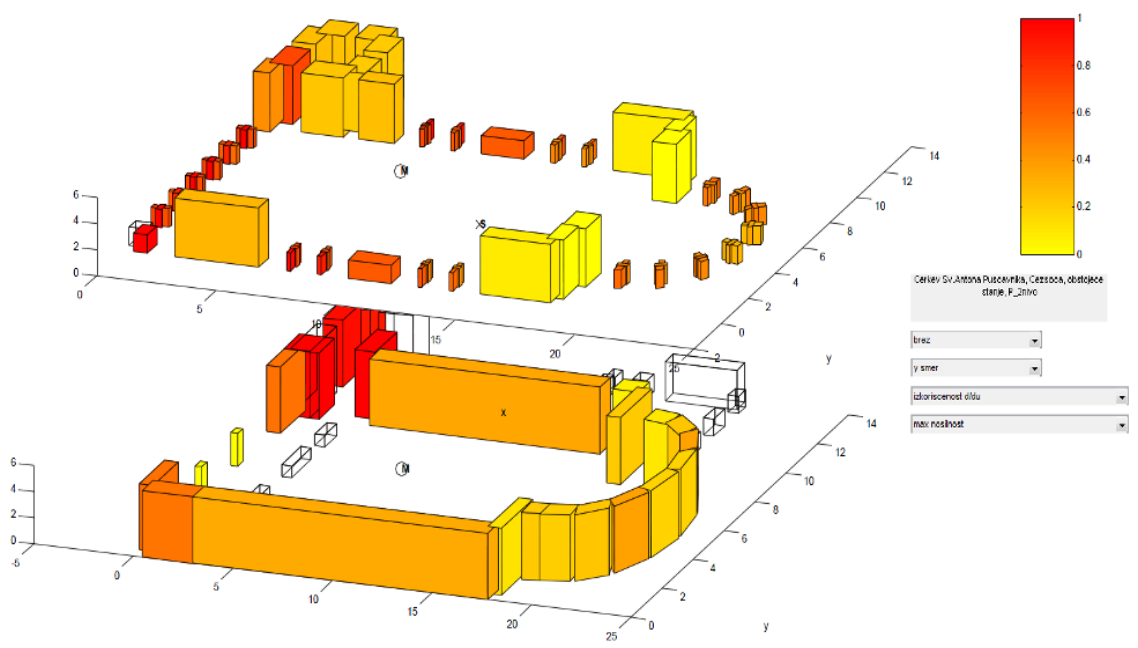

Figure 8: Actual/ultimate displacement ratio for limit state of a structure at two levels.

Recent research [6] has shown that for complex structures, such as churches, more realistic results can be obtained by using FME (Frame by Macro Elements) method, which takes into account the whole building response instead of just single storey response, and furthermore, allows modal analysis to be performed.

\section{Strengthening procedures}

In continuation, some of practically implemented strengthening procedures under post-earthquake renewal in the Posočje region are presented. There are also other strengthening procedures such as sewing of walls with grouted anchors, application of polymer grids or carbon fibre-reinforced polymer wraps, that won't be described in this paper.

Tying walls with steel ties (fig. 9) can be applied at the level of individual inter-storey floor structures. In this way the integrity of a structure is improved, the horizontal load is distributed to the walls according to their stiffness, and the walls are better protected against excessive rocking and possible failure in the out-of-plane direction. 

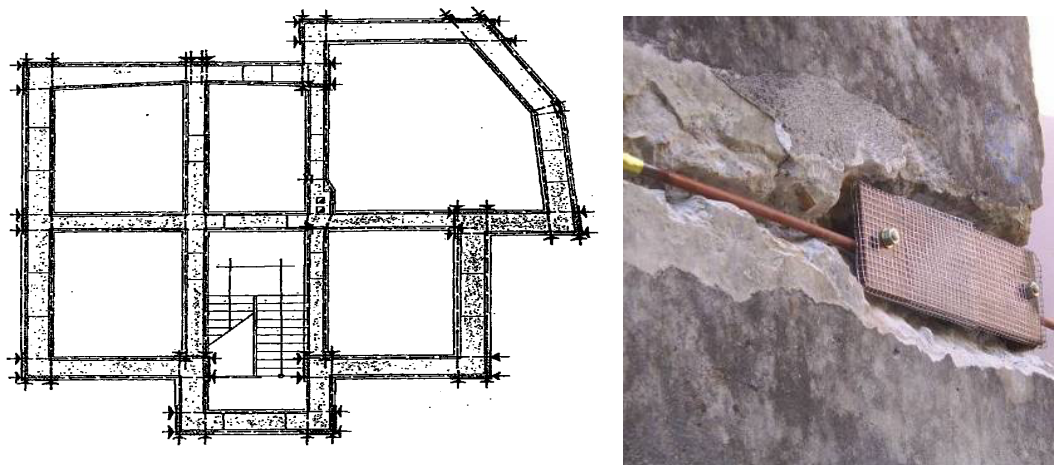

Figure 9: $\quad$ Tying of walls with steel ties.

Reinforced concrete tie-beams can be constructed at floor or roof level and anchored onto the load-bearing walls. Such method of strengthening improves structural integrity of a building and ensures more uniform behaviour of the structure. By anchoring the roof into the tie-beams possible uncontrolled movements of the roof elements and failure of head-walls is prevented.

Injected anchors applied at the middle of the wall's cross section can, if properly designed and executed, successfully replace steel ties or reinforced tiebeams. This solution is similar to method used by the old builders. Namely connecting walls with ties, installed in the middle of the wall, has been prescribed even after the 1895 earthquake in Ljubljana [4]. Injected anchors can perform either as untensioned steel reinforcement or prestressed tendons. The execution of a borehole and examples of application are shown on fig. 10.

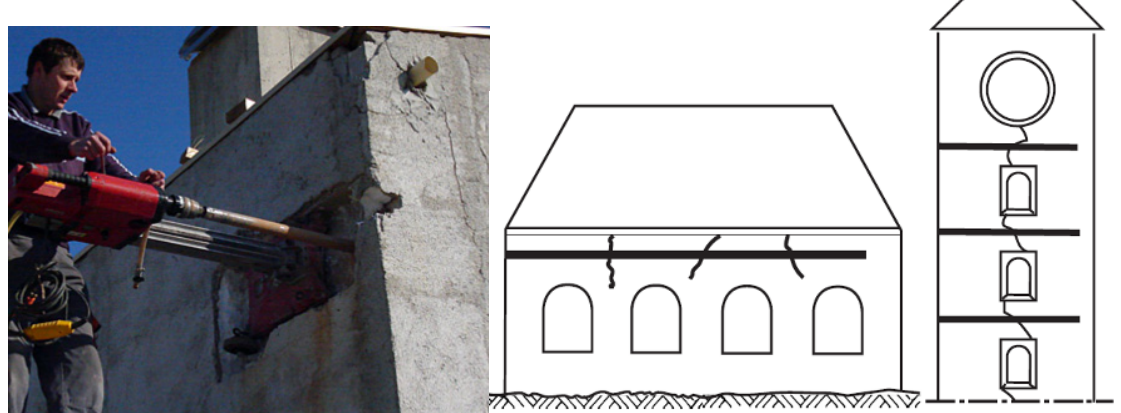

Figure 10: Application of injected anchors [3].

Repointing can be applied where bed-joints are relatively level, the mortar is poor and units are good. The resistance of a wall to vertical and lateral loading can be considerably improved by replacing a part of the existing mortar with mortar of better quality [5]. Although repointing is usually applied on brick 

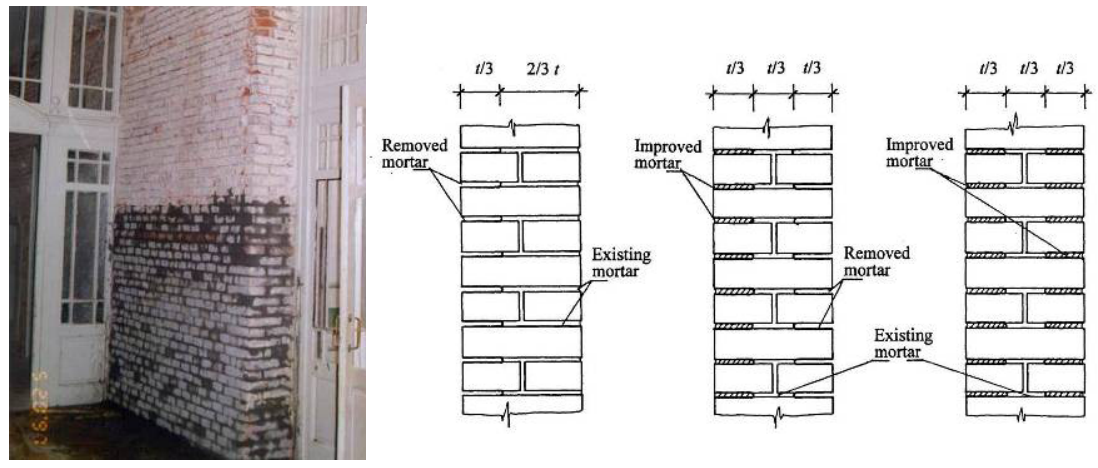

Figure 11: $\quad$ Repointing of a brick-masonry wall [5].

masonry, some authors [1] propose the application of the procedure also on stone masonry walls.

Injection grouting can be used to improve the mechanical properties of two or three-leaf stone masonry walls. Because of inadequate connections between separate stones, voids and poor quality of used mortar, the load bearing capacity of such walls, especially towards horizontal loading, is not sufficient. With grout injection technique, grout (liquid mixture made of water, binder and additives) is injected into a masonry wall (fig. 12) under moderate pressure (2-3 bars). The aim of the technique is to achieve better bonding between separate stones and leafs after the hardening of the injected material, and consequently to improve mechanical properties of the masonry. Work on site showed, that it is best to carry out injection grouting of all load-bearing walls, over their whole height of the structure. Damage that occurred in the buildings after strengthening and repeated earthquake has shown that grouting only parts of walls is not a good solution.

Strengthening of walls by applying reinforced cement coating (fig. 13) is usually used for strengthening of brick masonry. However, for more vulnerable structures such as bell towers, it can also be used for strengthening the stone
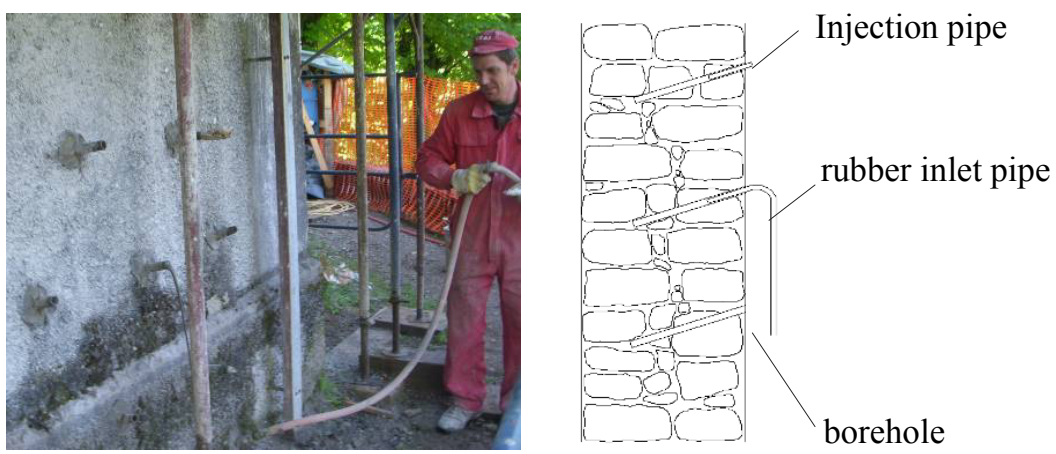

Figure 12: Injection grouting. 


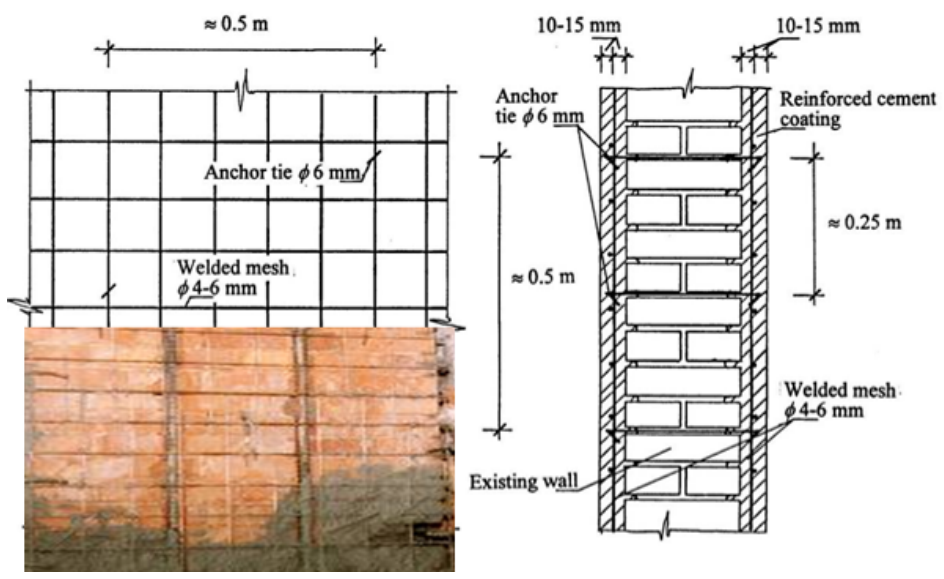

Figure 13: Application of reinforced cement coating on brick-masonry walls.

masonry in combination with application of steel ties and grout injection. By thicker layers amount of reinforcement can be increased and torcrete technology can be applied.

Strengthening the foundations. In the case of weak or shallow foundations it is necessary to widen or deepen them. That is achieved by constructing a reinforced concrete tie-beam along the outside edge of the foundations (fig. 14). New tie-beam should be anchored into the existing foundations by transverse anchors.

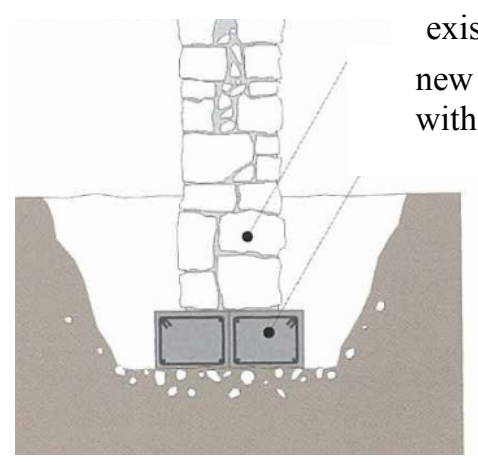

existing wall new foundation with r.c. tie beam

Figure 14: Strengthening of foundations [2].

Only carefully designed combination of strengthening procedures can provide adequate behaviour of the structure during the impact of an earthquake. An example of combining several strengthening procedures on the nave of St. Anton the Hermit is shown in fig. 15. 


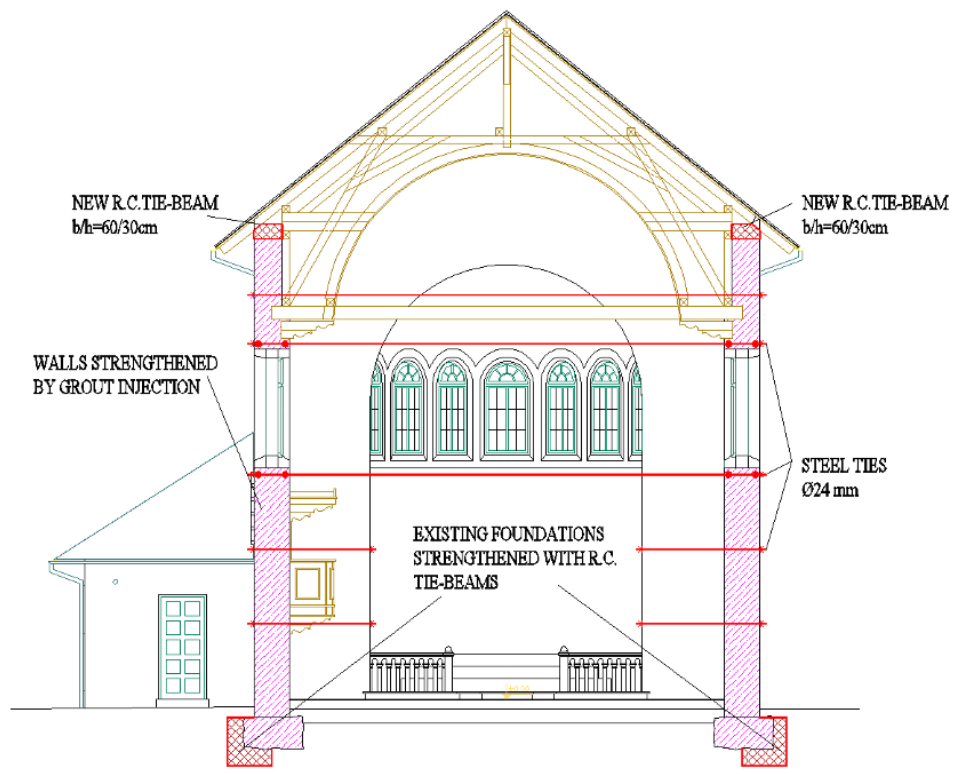

Figure 15: Strengthening procedures on the nave of St. Anton the Hermit's church.

\section{Conclusion}

Some of the basic strengthening procedures applied on churches in the Posočje region are presented. Although churches are mostly of better quality than ordinary buildings, because of their typical design, strengthening procedures are more complex and demanding. Because churches are usually under cultural heritage protection, strengthening must be performed without substantial modifications of the basic structural system. Therefore, adequate seismic resistance is harder to achieve compared to ordinary buildings. In order to achieve optimal results, strengthening procedures should be carefully planned and implemented, based on the results of the preliminary investigations and static and seismic analysis.

\section{References}

[1] Corradi, M., Tedeschi, C., Binda, L., Borri, A., Experimental evaluation of shear and compression strength of masonry before and after reinforcement: Deep repointing. Construction and Building Materials, Vol. 22, Issue 4, pp. 463-472, 2008

[2] Deu, Ž., Renewal of residential buildings in the Slovenian countryside (in Slovenian). Kmečki glas, Ljubljana, 277 p., 2004 
248 Earthquake Resistant Engineering Structures VIII

[3] Gigla, B., Bond strength of injection anchors as supplementary reinforcement inside historic masonry. 13th International Brick and Block Masonry Conference Amsterdam, July 4-7, 10 p., 2004

[4] Tomaževič, M. Expert evaluation of seismic strengthening of masonry buildings with injected anchors. ZAG, Ljubljana, 4 p., 1998

[5] Tomaževič, M., Earthquake-resistant design of masonry buildings. London: Imperial College Press, 268 p., 1999

[6] Naglič, A., Seismic analysis of religious buildings (in Slovenian). Graduation thesis, University of Ljubljana, Faculty of civil engineering and geodesy, Ljubljana, 146 p., 2011 